\title{
Serological evidence of natural exposure of camels (Camelus dromedaries) to foot and mouth disease virus
}

\author{
M R Yousef ${ }^{1,2 *}$ K S Mazloum ${ }^{3}$, H M Al-Nakhli ${ }^{3}$ \\ 1. Department of Foot \& Mouth Disease, Veterinary Serum and Vaccine Research Institute, Abbasia, 11381 \\ Cairo, Egypt. 2. Central Veterinary Diagnostic Lab., 11454 Riyadh, Ministry of Agriculture, KSA. 3. National \\ Agriculture and Animal Resources Research Center, Ministry of Agriculture, 11484 Riyadh. KSA \\ * Corresponding author email: mrabie@ymail.com \\ Received: 11-09-2011, Accepted: 09-10-2011, Published Online: 18-12-2011 \\ doi: $10.5455 /$ vetworld.2012.197-200
}

\begin{abstract}
The World Organization for Animal Health (OIE) Code chapter on FMD includes camelids as being susceptible species to FMD similar to cattle, sheep, goats and pigs. A total of 376 field camel sera, collected from different regions of Riyadh and AlQassim Province in the Kingdom of Saudi Arabia, were screened for the presence of antibodies produced against 3ABC nonstructural proteins (NSP) of FMDV using a commercially available kit , PrioCHECK ${ }^{\circledast}$ FMDV NS. Sera that tested positive on NSP were screened for serotype-specific antibodies towards the seven serotypes of FMD virus using liquid phase blocking ELISA. Only 24 out of $376(6.3 \%)$ serum samples were positive for antibodies against NSP. All sera that tested positive on NSP and screened for antibodies against all the seven FMDV serotypes (O, A, C, Asia 1, SAT 1, SAT 2 and SAT 3) were found positive for antibodies against serotype $\mathrm{O}$. This lower seroprevalence of $(6.3 \%)$ reveals that dromedaries appear however as being susceptible to infection with FMDV serotype $\mathrm{O}$, but they are unlikely to play any significant role in the natural epidemiology of FMD.
\end{abstract}

Key Words: 3ABC, Camel, ELISA, FMD, Saudi Arabia

To cite this article : Yousef MR, Mazloum KS, Al-Nakhli HM (2012) Serological evidence of natural exposure of camels (Camelus dromedaries) to foot and mouth disease virus, Vet. World. 5(4):197-200, doi: 10.5455/ vetworld.2012.197-200.

\section{Introduction}

Foot-and-mouth disease (FMD) is a highly contagious disease affecting domestic and wild cloven hooved animals (Artiodactyla). It remains the single most difficult animal viral disease to control and causes severe economic losses to the livestock industry (Alexandersen et.al. 2003; Alexandersen and Mowat, 2005). Camelids belong to the suborder Tylopoda, order Artiodactyla (Wernery and Kaaden, 2002). The World Organization for Animal Health (OIE) code chapter on FMD includes the Camelidae as susceptible species to FMD, similar to cattle, pigs, sheep and goats but infection dynamics vary across all these species (OIE, 2009).

The Camelidae inhabit countries in North and East Africa, Middle and East Asia as well as South America where FMD is endemic (Du et.al. 2009). Opinions vary widely whether animals of the Camelidae family are susceptible to FMD or not, or if they may serve as viral reservoirs. The two closely related camel species of Bactrian and dromedary camels possess noticeably different susceptibility to FMD virus (Larska et.al. 2009). Several authors described FMD outbreaks in Mongolia in the 1970s, and more recently in 2001 as affecting Bactrian camels reared together with diseased cattle, goats and sheep, although no samples from camels were tested and the diagnosis was done only on clinical observation (V. Kouba 2005, cited in Larska et.al. 2009). Bactrian camels can relatively easily be infected with FMDV under experimental conditions and develop frank clinical disease (Larska et.al. 2009), while Several investigations appear to indicate that dromedaries are of low susceptibility to inoculation with FMD virus serotype $\mathrm{O}$ but that they do not present a risk in transmitting FMD to susceptible animals (Wernery and Kaaden, 2004; Alexandersen et.al. 2008). However, Kumar et.al.(1983) described isolation of FMDV serotype $\mathrm{O}$ from one of two randomly selected dromedaries in India and Moussa et.al. (1987) in Egypt have described a strain of type O FMD virus was isolated in Giza from a camel with vesicular, ulcerative stomatitis and they suggested that dromedaries are susceptible to natural FMD.

The aetiological agent, foot and- mouth disease virus (FMDV), is classified with the Aphthovirus genus as a member of the Picornaviridae family and exists as 
many subtypes and variants within seven different serotypes (A, O, C, Asia1, and South African Territories 1, 2, and 3) (Belsham, 2005). FMDV is a small nonenveloped virus with an $8.5-\mathrm{kb}$ genome which codes for structural as well as nonstructural proteins (NSPs).The viral capsid is composed of four structural proteins, VP1, VP2, VP3 and VP4 (Fry et.al. 2005). Antibodies principally to the structural proteins of FMDV were induced in vaccinated animals, whereas infected animals produce antibodies to both the structural and nonstructural proteins. Therefore, assays demonstrating antibodies against non-structural proteins have potential to differentiate infected animals from those that have been vaccinated (Berger et.al. 1990; Rodriguez et.al. 1994; De Diego et.al. 1997; Clavijo et.al. 2004).

Outbreaks of FMD repeatedly occur among cattle, sheep and goats in various regions of Saudi Arabia (Hafez et.al. 1993). Camels are frequently moved across the desert inside Saudi Arabia in an area that experienced FMD outbreaks in cattle and small ruminants so camels may play a possible role in the transmission of FMDV and may carry FMDV over very long distances and across borders. This study aimed to investigate the serological evidence of natural exposure of camels (Camelus dromedaries) to FMD virus, by investigating the presence of antibodies towards non structural proteins (NSP) using competitive ELISA and structural proteins using blocking ELISA for antibodies towards the seven serotypes of FMD virus, to evaluate the role of camels in the natural epidemiology of FMD in Saudi Arabia.

\section{Materials and Methods}

A total of 376 random field camel sera were collected from different regions of Riyadh (Thumamah, AlGway'iyyah, Al-Aflaj, Wadi ad-Dawasir, Dawadmi, Thadig) and Al-Qassim Province between Jan 2010Julay 2010. Sera were taken from camel, which were grazing together with cattle, sheep, goats and free ranging wild herbivores. No clinical evidence of FMD was observed in camels at time of sampling, although many of them had daily contact with infected ruminants. Whole blood was collected from the jugular vein of each animal randomly selected from the herd and the blood was stored at room temperature until the serum was separated (3-4 h on average). The serum was collected; then transferred into a sterile cryotube and stored at $-20^{\circ} \mathrm{C}$ until tested for the presence of antibodies produced against NSP of FMDV. Sera that tested positive on NSP were screened for serotype-specific antibodies towards the seven serotypes of FMDV.

The PrioCHECK $®$ FMDV NS: Commercial ELISA kit produced by Prioncs Lelystad B.V.The Netherlands for detection of antibodies against the non-structural proteins (NSP) of FMDV that could be used to test serum samples of cattle, sheep, goats, camel and pigs. The assay was performed as described by the manufacture. Briefly, test plates of the kit contain FMDV NSP captured by the coated $3 \mathrm{ABC}$ specific $\mathrm{mAb}$. The test is performed by dispensing the test samples to the wells of a test plate. After incubation the plate is washed and the conjugate [mAb horseradish peroxidase (mAb-HRPO)] is added. Specific antibodies directed against the NSP, that may be present in the test sample will bind to the $3 \mathrm{ABC}$ protein and will block the binding of the mAb-HRPO. After incubation, the plate is washed and the chromogen (TMB) substrate is dispensed. After incubation at room temperature $\left(22 \pm 3^{\circ} \mathrm{C}\right)$ the color development is stopped. Color development measured optically at a wavelength of $450 \mathrm{~nm}$ and results were expressed as a percentage inhibition (PI) of the controls and the test sera which calculated according to the formula below:

$\mathrm{PI}=100-\left(\mathrm{OD}_{450}\right.$ test sample/OD $\left.{ }_{450} \mathrm{Neg}.\right) \times 100$

Sera with PI $\geq 50 \%$ were scored as positive (Sorensen et. al.1998).

Liquid phase blocking enzyme immunoassay (LPBE): Commercial LPBE kit produced by FMD World Reference Laboratory (WRL), Pirbright, UK was used for detection of antibodies to foot-and-mouth disease virus. LPBE technique was developed according to Hamblin et.al. (1986 a, b). The LPBE was applied according standard operating procedure supplied with the kit. Briefly, the test is based upon specific blocking of liquid phase FMD antigen by antibodies in the test serum sample. ELISA plates are coated with anti-FMD antibody. Sera premixed with different serotypes of FMD antigen is then added to the coated plates. If antibodies are present in the test sera, they will block the antigen and prevent it from binding to the coating antibody. If there are no specific antibodies in the test sera then the antigen will be available to be trapped on the plate, this will be detected by a positive colour indicating negative test results.

\section{Results and Discussion}

FMDV type $\mathrm{O}$ is endemic in all countries of the Middle East region (Samuel and Knowles, 2001). FMD is endemic in Saudi Arabia with control 
Serological evidence of natural exposure of camels to foot and mouth disease virus

Table-1: Study areas from where the samples were taken and results of sample testing

\begin{tabular}{lccc}
\hline Region & No. of samples & 3ABC +VE (\%) & Specific serotype antibody \\
\hline Thumamah & 87 & $8(9.1 \%)$ & 0 \\
Al-Gway'iyyah & 42 & $3(7.1 \%)$ & 0 \\
Al-Aflaj & 55 & $1(1.8 \%)$ & 0 \\
Wadi ad-Dawasir & 60 & $8(13.3 \%)$ & 0 \\
Dawadmi & 75 & $2(2.6 \%)$ & 0 \\
Thadig & 28 & $1(3.5 \%)$ & 0 \\
Al-Qassim & 29 & $1(3.4 \%)$ & 0 \\
Total & 376 & 24 & \\
\hline
\end{tabular}

strategies focusing on vaccination of cattle and small ruminants, while camels are not included in the vaccination campaigns. Camels are frequently moved across the desert due to seasonal variations, availability of grazing land, fairs etc. may lead to dissemination of various diseases from affected animals to other healthy animals in disease free region.

Our results in table (1) revealed only 24 out of 376 (6.3\%) serum samples from Riyadh and AlQassim Province were positive for antibodies against NSP. All sera that tested positive on NSP and screened for antibodies against all the seven FMDV serotypes (O, A, C, Asia 1, SAT 1, SAT 2 and SAT 3) were found positive for antibodies against serotype $O$. These results indicate serological evidence of camel exposure to FMD infection that could be attributed to movement of camels in an area that experienced FMD outbreaks and camels may come in contact with infected fully susceptible animals such as cattle and small ruminants.

The susceptibility of cloven-hoofed livestock was postulated by Du et.al. (2009) who found the structures of their integrin receptors were more susceptible to binding with the viral surface, which would lead to much greater viral replication and disease within these species and there is close relationships among the integrins of cloven-hoofed

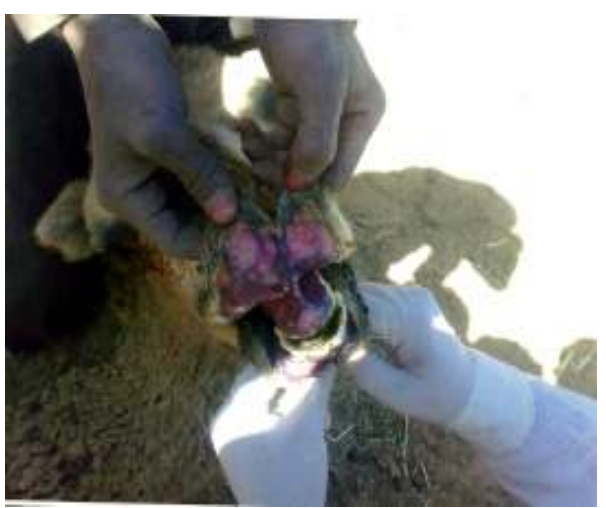

animals, including Bactrian camels, pigs and cattle, that are susceptible to FMDV infection. In this study a lower FMD seroprevalence of camel examined sera obtained was in agreement with Alexandersen et.al. (2008) and Wernery and Kaaden (2004) who found that camels are low susceptibility and do not present a risk in transmitting FMD to susceptible animal species.

On the other hand, Farag et.al. (1998) were not able to isolate FMDV from 30 probang samples harvested from dromedaries on different farms in Saudi Arabia where FMD was said to be endemic. Moreover; pathological lesions of suspected FMD (severe mouth ulceration) were recorded in a camel (Fig.1a-b) at Northern Borders province in Saudi Arabia at Jan 2008, where; no FMDV was detected by Antigen FMD ELISA in that tested collected samples in the central veterinary diagnostic lab. in Riyadh (unpublished data). This negative ELISA result does not necessarily mean that the sample was truly negative as it may contain concentrations of virus insufficient for the ELISA to detect (Ried et.al. 2001).

\section{Conclusion}

We could be concluded that: dromedaries appear however as being susceptible to infection with FMDV serotype $\mathrm{O}$, but they are unlikely to play any significant role in the natural epidemiology of FMD.

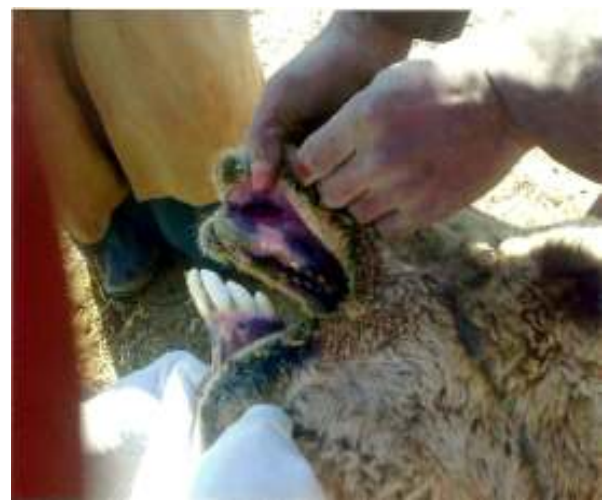

Figure : Severe mouth ulceration of camel reveals a suspected case of FMD 


\section{Acknowledgement}

The authors are grateful for the financial support of Agriculture and Animal Resources Research Center, Ministry of Agriculture grant no.32/1/48/015/004/3 in conducting this study.

\section{Conflict of interest}

Authors declare that they have no conflict of interest.

\section{References}

1. Alexandersen S. and Mowat N. (2005). Footand-mouth disease: host range and pathogenesis. Curr. Top. Microbiol. Immunol., 288:9-42.

2. Alexandersen S., Zhang Z., Donaldson A.I., Garland A.J. (2003). The pathogenesis and diagnosis of footand-mouth disease. J. Comp. Pathol., 129: 1-36.

3. Alexandersen S., Wernery U., Nagy P., Frederiksen T., Normann P. (2008). Dromedaries (Camelus dromedarius) are of Low Susceptibility to Inoculation with Foot-and-Mouth Disease Virus Serotype O. J. Comp. Path., 139: 187-193.

4. Clavijo A., Wright P., Kitching P. (2004). Developments in diagnostic techniques for differentiating infection from vaccination in foot andmouth disease. Vet. J., 167: 9-22.

5. Belsham G.J.(2005).Translation and replication of FMDV RNA. Curr. Top. Microbiol. Immunol., 288:43-70.

6. Berger H-G., Straub O.C., Ahl R., Tesar M., Marquardt O. (1990). Identification of foot-andmouth disease virus replication in vaccinated cattle by antibodies to non-structural virus protein. Vaccine, 8:213-216.

7. De-Diego M., Brocchi E., Mackay D., De Simone F. (1997).The nonstructrural polyprotein $3 \mathrm{ABC}$ of foot-and-mouth disease as a diagnostic antigen in ELISA to differentiate infected from vaccinated cattle. Arch. Virol., 142: 2021-2033.

8. Du J., Gao S., Chang H., Cong G., Lin T., Shao J., Liu Z., Liu X., Cai X. (2009).Bactrian camel (Camelus bactrianus) integrins avb3 and avb6 as FMDV receptors: Molecular cloning, sequence analysis and comparison with other species. Vet. Immunol. Immunopathol.,131:190-199.

9. Farag M.A., Al-Sukayran A., Mazloum K.S., AlBokmy A.M. (1998). The susceptibility of camels to natural infection with foot and mouth disease virus. Assiut Vet. Med. J., 40: 201-211.

10. Fry E.E., Stuart D.I., Rowlands D.J. (2005). The structure of foot-and-mouth disease virus. Curr. Top. Microbiol. Immunol., 288: 71-101.

11. Hamblin C., Barnett I.T.R., Hedger R.S. (1986a). A new enzyme-linked immunosorbent assay (ELISA) for the detection of antibodies against foot and mouth disease virus. Development and method of ELISA. J. Immunol. Methods, 93:115-121.

12. Hamblin C., Barnett I.T.R., Crowther J.R. (1986b). A new enzyme linked immunosorbent assay (ELISA) for the detection of antibodies against foot and mouth disease virus. J. Immunol. Methods, 93:123-129.

13. Hafez S.M., Farag M.A., Mazloum K.S., ALBokmy A.M. (1993). Application of double sandwich enzyme-linked immunosorbent assay for the diagnosis of foot and mouth disease in Saudi Arabia. Dt. tierärztl. Wschr., 100: 103-106.

14. Kumar A., Prasad S., Ahuja K. L., Tewari S. C., Dogra S. C., Garg D. N.(1983). Distribution pattern of foot-and-mouth disease virus types in North-West India (1979-1981). Haryana Veterinarian, 22:28-30.

15. Larska M., Wernery U., Kinne J., Schuster R., Alexandersen G., Alexandersen S. (2009) Differences in the susceptibility of dromedary and Bactrian camels to foot-and-mouth disease virus. Epidemiol. Infect., 137:549-554.

16. Moussa A. A. M., Daoud A., Omar A., Metwally N., El-Nimr M., McVicar J. W. (1987). Isolation of foot-and-mouth disease virus from camels with ulcerative disease syndromes. J.Egypt.Vet. Med.Assoc., 47:219-229.

17. Reid S.M., Ferris N.P., Hutchings G.H., Zhang Z., Belsham G.J., Alexandersen S. (2001): Diagnosis of foot-and-mouth disease by real-time fluorogenic PCR assay. Vet. Rec., 149: 621-623.

18. Rodriguez A., Dopazo J., Saiz J.C., Sobrino F. (1994). Immunogenicity of non-structural protein of foot-and-mouth disease virus: differences between infected and vaccinated swine. Arch.Virol., 136: 123131.

19. Samuel A.R. and Knowles N.J. (2001) Foot and mouth disease type $\mathrm{O}$ viruses exhibit genetically and geographically distinct evolutionary lineages (topotypes). J.Gen.Virol., 82:609-621.

20. Sørensen K.J., Madsen K.G., Madsen E.S., Salt J.S., Nqindi J., Mackay D.K.J. (1998). Differentiation of infection from vaccination in foot-and-mouth disease by the detection of antibodies to the non-structural proteins $3 \mathrm{D}, 3 \mathrm{AB}$ and $3 \mathrm{ABC}$ in ELISA using antigens expressed in baculovirus. Arch.Virol., 143: 1461-1476.

21. Wernery U. and Kaaden O.R. (2002). Infectious Diseases in Camelids. Oxford: Blackwell Science: pp. 3-17.

22. Wernery U. and Kaaden O. R. (2004). Foot-andmouth disease in camelids: a review. Vet. J., 168:134142.

23. World Organisation for Animal Health (OIE) (2009). Foot and mouth disease. OIE Terrestrial Manual 2009, Chapter 2.1.5.http://www.oie.int/ fileadmin/Home/.../2.01.05_FMD.pdf. 